\title{
A UTILIZAÇÃO DA LOUSA DIGITAL NA FORMAÇÃO DOCENTE DOS ANOS INICIAIS NO NÚCLEO DE TECNOLOGIA EDUCACIONAL DO MUNICÍPIO DE CORUMBÁ-MS
}

\author{
Mishelly Ocuda Henrique de Lima Tinôco \\ mishelly18@hotmail.com \\ Universidade Norte do Paraná - Brasil
}

\begin{abstract}
Resumo. Este artigo é resultado da formação continuada realizado pelo Núcleo de Tecnologia Educacional de Corumbá no ano 2014 tendo como público alvo docentes do ensino fundamental da rede estadual de educação. O objetivo geral: Propiciar aos docentes recursos tecnológicos que enriqueçam suas metodologias, por meio das mídias digitais. Objetivos específicos são: a) Subsidiar as metodologias aplicadas com o uso da lousa digital; b) Utilizar a lousa digital concomitante com os applet de simulação e de animação e os jogos on-line e off-line; c) Dinamizar a consolidação dos direitos de aprendizagem dos alunos nos anos iniciais. A importância dos recursos tecnológicos na sociedade, favorece as habilidades necessárias à construção do conhecimento, no desenvolvimento didático-pedagógico.
\end{abstract}

Palavras-chave: Lousa digital; Ensino fundamental; Formação continuada.

\section{Introdução}

O uso das mídias digitais está mais frequente na rotina dos alunos que frequentam as escolas públicas no século XXI, fazendo com que os docentes sejam mediadores de novos recursos, favorecendo ensino de qualidade aos alunos. Desta forma, o presente estudo tem a finalidade de apresentar o resultado do curso de formação continuada, oferecido para os docentes dos anos iniciais do $1^{\circ}$ ao $3^{\circ}$ anos do ensino fundamental das escolas da rede estadual de educação no ano de 2014 com a utilização da lousa digital proporcionando agilidade e prazer em desenvolver as atividades didático-pedagógicas propostas nas referidas etapas de ensino. Teve o objetivo geral: estimular o uso das mídias digitais nas metodologias dos anos iniciais do 
$1^{\mathrm{o}}$ ao $3^{\mathrm{o}}$ anos do ensino fundamental. Os objetivos específicos foram: a) propor a inovação nas metodologias dos docentes dos anos iniciais do ensino fundamental; b) estimular o uso da lousa digital concomitante com applet de animação e simulação, jogos online e off-line; c) dinamizar a consolidação dos direitos de aprendizagem. Os procedimentos de pesquisa foram de cunho bibliográfico, documental e de campo. As pesquisas documentais e bibliográficas consistiram nas leituras analíticas das fontes primárias e secundárias. Para coleta de pesquisa de campo foi utilizado um formulário online via Google Drive sendo realizada a tabulação dos gráficos no editor Excel.

Para tanto, este artigo está estruturado em quatro partes contemplando também o resultado da pesquisa de campo dividida em duas partes a primeira contempla a formação inicial e continuada; a segunda parte ressalta a utilização da lousa digital nas atividades didático pedagógicas, além da conclusão e referências na próxima seção.

\section{Breve histórico das atribuições da utilização dos recursos tecnológicos nas escolas de educação básica}

Com o avanço do sistema de informação o uso das tecnologias iniciou-se nas escolas em meados dos anos 1970 com o apoio das Instituições de Ensino Superior (IES) realizando estudos e pesquisas para a implantação das tecnologias na formação continuada mediante as diversas tentativas de projetos criados e realizados para a inserção das tecnologias na formação continuada do docente para complementar sua prática docente. Mas, somente em 1997 foi criado o Programa Nacional de Informática na Educação (ProInfo), respaldado pelo decreto $\mathrm{n}^{\mathrm{o}}$ 6.300 de 12 de dezembro de 2007 na qual, dispõe as atribuições do referido programa.

Aquele decreto disciplinou a utilização dos recursos tecnológicos no ensino e na aprendizagem dos alunos das escolas da rede pública de educação básica. Por conseguinte, o Ministério da Educação (MEC) tem como atribuição promover e implantar recursos tecnológicos que favoreçam a utilização nas atividades didático-pedagógicas e formação continuada aos profissionais da educação, disponibilizando mídias digitais na WEB 2.0 e meios 


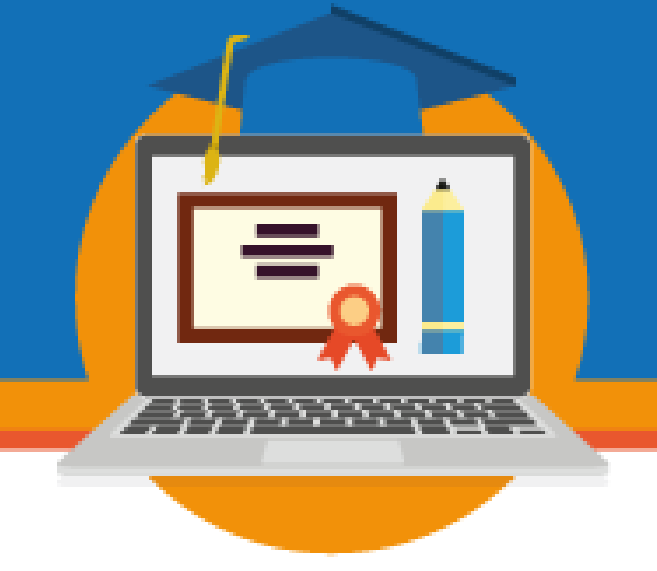

que possivelmente possam acompanhar o desenvolvimento das Tecnologias Digitais de Informação e Comunicação (TDIC), assim como as redes de educação do estado e do município têm como função disponibilizar a infraestrutura adequada para implantação dos ambientes tecnológicos nas unidades escolares.

Segundo Valente (1999), a política de implantação do ProInfo tem a peculiaridade de atender aos docentes das instituições públicas, buscando atender as especificidades dos docentes, a salvo que as atividades do programa são voltadas para professores que já possuem experiência com o uso das TIC.

Na mesma direção, Kenski (2007) afirma que o pedagogo conforme o tempo encaminhe e oriente o aluno diante das diversas possibilidades e formas de se interagir e conquistar o conhecimento ressaltando a importância ao acesso às demais informações estimulando e orientando o aluno na utilização adequada dos recursos tecnológicos disponíveis em sua rotina, cabendo ao docente associar as tecnologias para a valorização da aprendizagem dos alunos independente de sua faixa- etária ou etapa de ensino.

\section{Formação Continuada com a utilização da lousa digital para os professores dos anos iniciais no Núcleo de Tecnologia Educacional - NTE Corumbá}

O Núcleo de Tecnologia Educacional (NTE) de Corumbá em conformidade com suas atribuições tem o objetivo de estimular e propiciar formação continuada aos professores da rede estadual de educação com o uso das Tecnologias Digitais de Informação e Comunicação (TDIC).

A formação continuada docente tem a finalidade de complementar à formação inicial e ao longo de sua carreia, buscar melhorar sua prática pedagógica para o exercício de sua função quanto profissional da educação, ressaltando a utilização dos recursos tecnológicos no contexto educacional.

Em vista disto, a formação continuada com o recurso da lousa digital busca atender a solicitação dos professores que participam do programa Pacto Pela Alfabetização na Idade Certa (PNAIC), marcado pela crescente agilidade e atualização das informações, tornando-se 


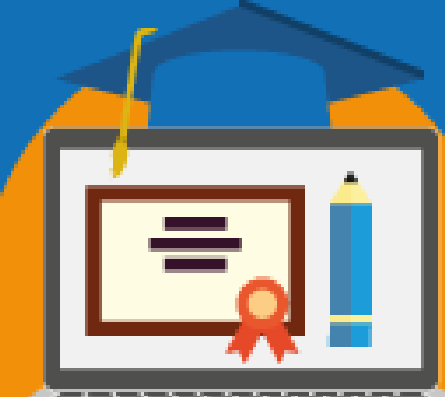

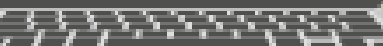

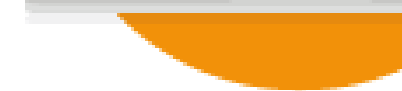

indispensável na educação, tendo como contribuição nas atividades didático-pedagógicas e com inúmeras possibilidades de utilizá-las e disponibilizá-las no âmbito educacional.

A proposta da formação foi norteada pelos cadernos de estudo do PNAIC, buscando atender os quadros de direitos de aprendizagem nos componentes curriculares de língua portuguesa e matemática, nas quais as atividades desenvolvidas foram jogos online e off-line, applet de simulação e animação e os recursos da lousa digital, propondo a utilização da lousa digital mesmo sem o acesso à internet, estimulando a familiaridade com estes recursos proporciona aos docentes dos anos iniciais mais interatividade em suas aulas, considerando as diversas tecnologias disponíveis nas escolas estaduais dos municípios de Corumbá e de Ladário.

As escolas mediante as disponibilidades das mídias digitais na escola pública e os diversos cursos de formação continuada oferecidos pelo MEC mediados pelo NTE de Corumbá, buscando também a possiblidade de novos projetos que atendam a utilização das Salas de Tecnologia Educacional (STE).

Em vista deste avanço, o Fundo Nacional de Desenvolvimento da Educação (FNDE) realizou no ano de 2011 o processo de entrega das lousas digitais pregão $n^{\circ} .72 / 2011$ nas escolas públicas em nível de Brasil para complementar o computador interativo (ProInfo Integrado) que permite a instalação da lousa digital em sistema operacional Linux Educacional, atribuindo ícones e funcionalidades diferenciadas dos portais de formação continuada do MEC, bem como os softwares que compõem o sistema da lousa digital propiciando ao usuário um layout facilitador e funcional para as atividades educacionais.

Por esta razão, a formação continuada surgiu da necessidade de utilizar os recursos midiáticos nos anos iniciais do ensino fundamental contemplando os direitos de aprendizagem do programa PNAIC, atendendo os quadros dos direitos de aprendizagem realizando atividades práticas que favoreçam a introdução, aprofundamento e consolidação dos blocos de conteúdos das disciplinas de língua portuguesa e matemática.

Em virtude do layout facilitador, a lousa digital foi utilizada como recurso para formação continuada no NTE - Corumbá onde propiciou interatividade para os professores do $1^{\mathrm{o}}$ ao $3^{\mathrm{o}}$ anos do ensino fundamental. Primeiramente, foram apresentados os componentes da 
lousa digital e suas funcionalidades, e os procedimentos de como ligar a lousa no projetor ProInfo Integrado (computador interativo). Assim, realizamos o processo de calibração da caneta, e como iniciamos a utilização da lousa digital com os recursos disponíveis no layout da lousa propiciando um momento para familiaridade dos recursos oportunizando segurança com o manejo da caneta. Após todos os 23 professores manusearem as funcionalidades da lousa iniciamos as atividades on-line com os recursos dos applet de simulação e animação, com atividades de ábaco, jogo da memória da tabuada 2 ao 9, resolvendo multiplicações e formando palavras.

Considerando a diversidade dos jogos que contemplam a WEB 2.0 utilizamos alguns jogos do site escola games: a batalha dos números, que proporciona a introdução das atividades com os sinais de maior e menor, robô lógico possibilita a resolução de contas de subtração proporcionando a utilização do teclado virtual da lousa digital. Também foi estimulado a utilização dos jogos off-line com o repositório digital disponível via google drive, orientando o docente para realizar o download para execução dos jogos posteriormente utilizar na lousa digital. Conforme a interatividade dos jogos e a pouca familiaridade com os recursos midiáticos os docentes demonstraram agilidade no manejo e as funcionalidades da lousa digital.

Conforme resolução vigente 2.491 de 8 de dezembro de 2011, dispõe a implantação da STE e as atribuições do professor gerenciador de tecnologias educacionais e recursos midiáticos (PROGETEC), sendo uma das atribuições principais oferecer formação continuada com a utilização das mídias para os professores regentes. Desta forma, o PROGETEC ministra as formações preferencialmente na hora atividade dos professores. No NTE, os professores realizaram o referido curso em momento presencial com a carga horária de 20 horas.

Após um ano de formação foi realizada uma pesquisa de campo em três escolas estaduais de Corumbá. As formações ocorreram nas escolas e no NTE. Desta forma, a pesquisa foi dividia em duas partes: a primeira busca verificar o perfil dos docentes entrevistados para melhor entender sua formação inicial, considerando suas especificidades em participar das formações continuadas oferecidas pelo NTE e pelo PROGETEC das respectivas unidades 


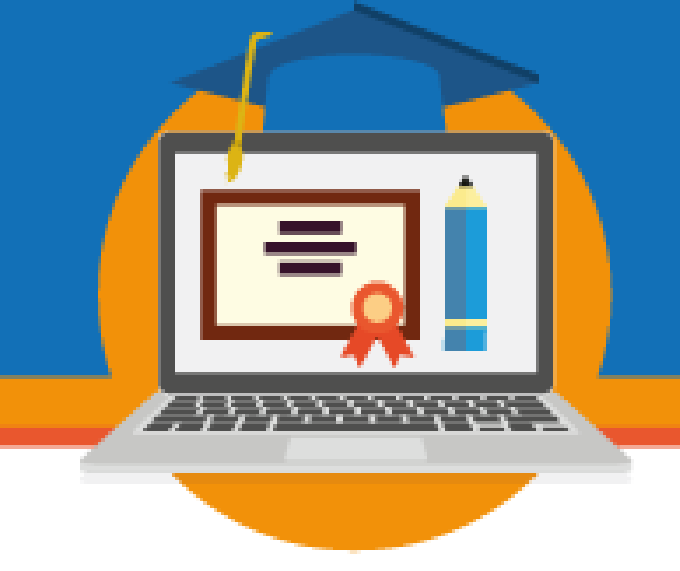

escolares; a segunda parte busca salientar a utilização das mídias nas atividades didáticopedagógicas desenvolvidas pelos professores regentes do $1^{\circ}$ ao $3^{\circ}$ anos do ensino fundamental.

Considerando o anonimato das referidas escolas serão determinadas escolas A uma escola da parte alta da cidade de médio porte, B a unidade escolar considerada um pouco mais central de médio porte, e $\mathrm{C}$ a unidade escolar extensão da escola polo da capital, pequeno porte.

Ao analisar as respostas dos docentes entrevistados constatou-se que na figura 1, 83\% dos docentes dos seis entrevistados possuem somente a graduação e 17\% ou seja, 01 (um) docente possui formação técnica. Vale ressaltar, que a matriz curricular do curso técnico em normal médio da rede estadual de educação de Mato Grosso do Sul possui a disciplina de tecnologia na educação e no campus do Pantanal (UFMS) a disciplina de educação, mídias e tecnologias é oferecida como disciplina complementar não sendo obrigatória.

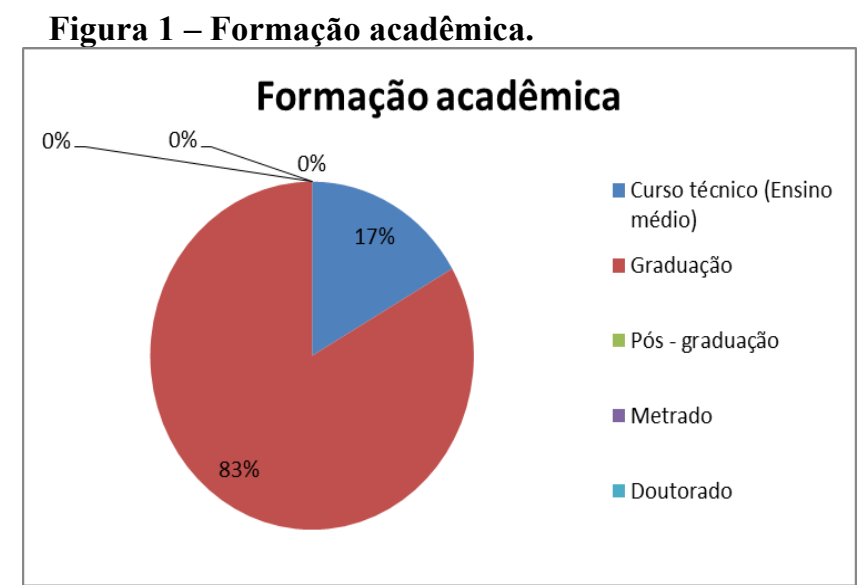

Fonte: Elaboração da autora com base no questionário aplicado.

Assim, ao analisar as figuras 2 e 3 podemos verificar que 50\% dos docentes realizaram formação continuada com o uso da lousa digital no NTE de Corumbá e 67\% realizaram o mesmo curso de formação continuada oferecido em escolas estaduais, sendo constatado que está em construção o processo de utilização dos recursos midiáticos nas atividades desenvolvidas no âmbito educacional.

Figura 2 - Participação de formação continuada 


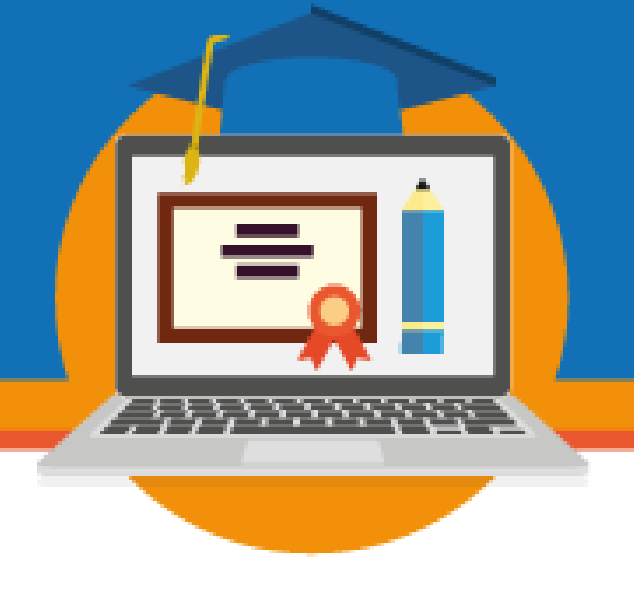

utilizando a lousa digital no NTE.

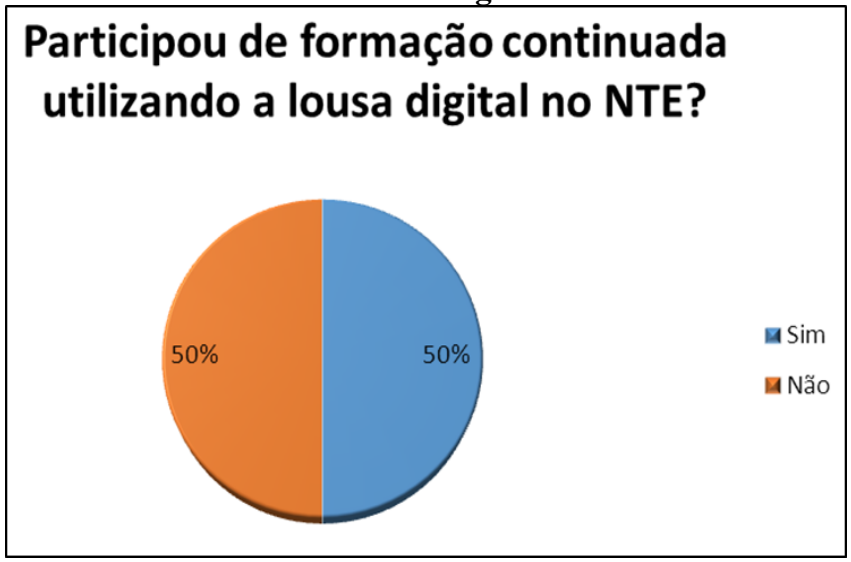

Fonte: Elaboração da autora com base no questionário aplicado.

Figura 3 - Participação de formação continuada utilizando a lousa digital na escola.

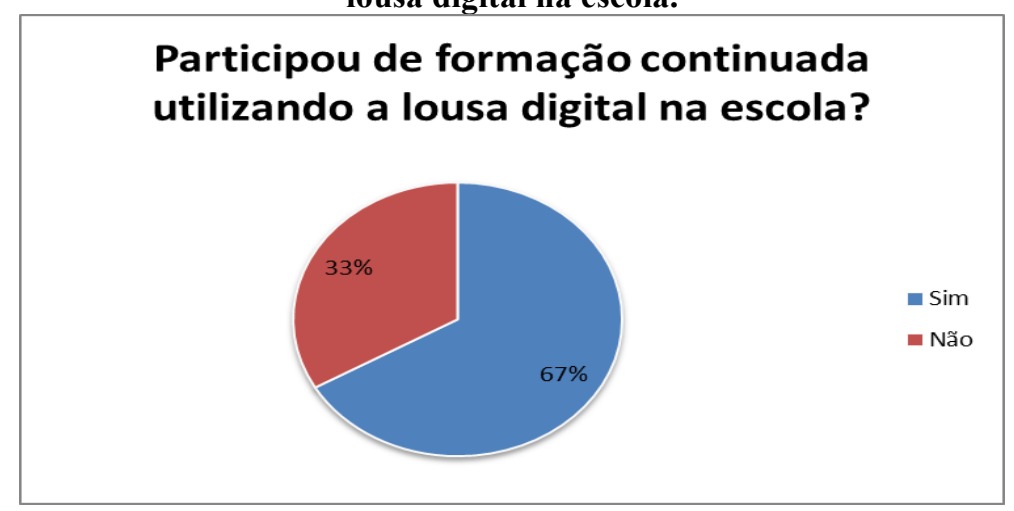

Fonte: Elaboração da autora com base no questionário aplicado.

Em vista do processo de formação continuada, Arruda (2004) ressalta que a inovação no trabalho docente pode ser constatada não pelo simples uso do computador em seu cotidiano, mas a partir do momento em que esses equipamentos alteram de forma significativa o olhar do docente diante do seu trabalho, suas concepções e seus modelos de ensino e de aprendizagem [...] sendo revisto até que ponto estes recursos midiáticos são novos no contexto escolar, pois 


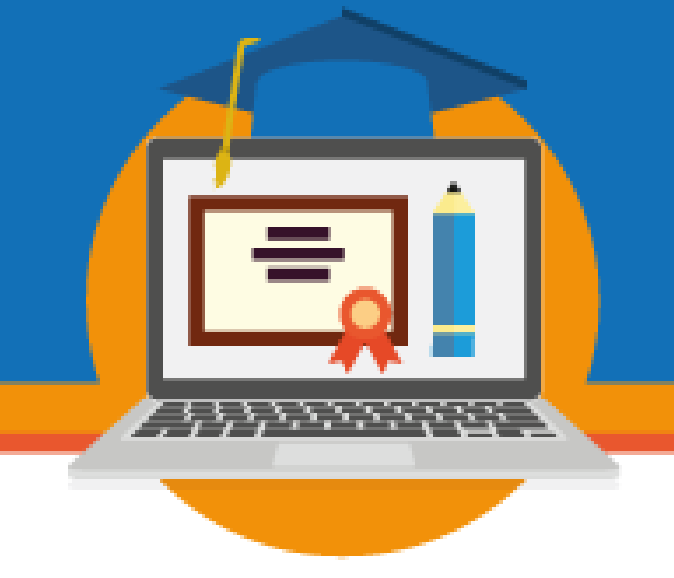

os alunos já possuem familiaridade em boa parte destes recursos, cabendo ao docente analisar a forma que está utilizando os recursos midiáticos disponíveis na escola.

Segundo Lopes (2016) a utilização dos recursos midiáticos pode fazer toda diferença no ensino dos docentes de forma que aplicabilidade venha inovar a aprendizagem dos alunos diariamente acompanham a evolução das mídias digitais. Assim, ao oportunizar o recurso lousa digital na formação continuada dos docentes dos anos iniciais tende a estimular a interatividade com novas possibilidades didático metodológicas, contribuindo para melhor interatividade meios digitais disponíveis na WEB 2.0 como os applet de animação, simulação, jogos on-line e off-line propiciando hábitos inovadores no fazer pedagógico da rede pública de ensino.

\section{Utilização da lousa digital como recurso didático - metodológico do $1^{\circ}$ ao $3^{\circ}$ ano} dos anos iniciais do fundamental nas escolas estaduais dos munícipio de Corumbá e de Ladário.

Conforme os Parâmetros Curriculares Nacionais (PCN) do ensino fundamental (1998) ressalta que as tecnologias é um traço para a cultura, tendo como objetivo fundamental saber utilizar os recursos tecnológicos de forma que venha a contribuir com o conhecimento e desenvolvimento do aluno dos anos iniciais apresentando a tecnologia como motivadora para a pesquisa e facilitadora da assimilação do conhecimento mediado pelo professor.

Desta forma, em continuidade com a segunda etapa da pesquisa de campo foi questionado aos docentes quais são recursos mais utilizados no planejamento diário, considerando a utilização dos recursos da lousa digital, quadro verde, giz, apagador e livro didático, sala de tecnologia educacional (STE), data show e DVD TV escola.

Conforme a figura $4,50 \%$ dos docentes utilizam quadro verde, giz, apagador e livro didático nas atividades cotidianas e 50\% utilizam a STE. Por outro lado, comprovou-se que nenhum dos entrevistados utilizaram a lousa digital como recurso de apoio aos conteúdos ministrados. 


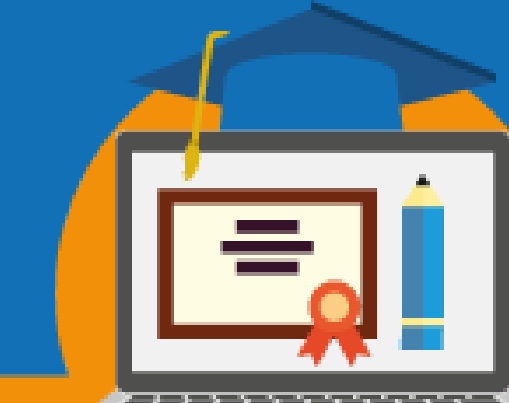

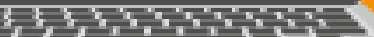
do professor.

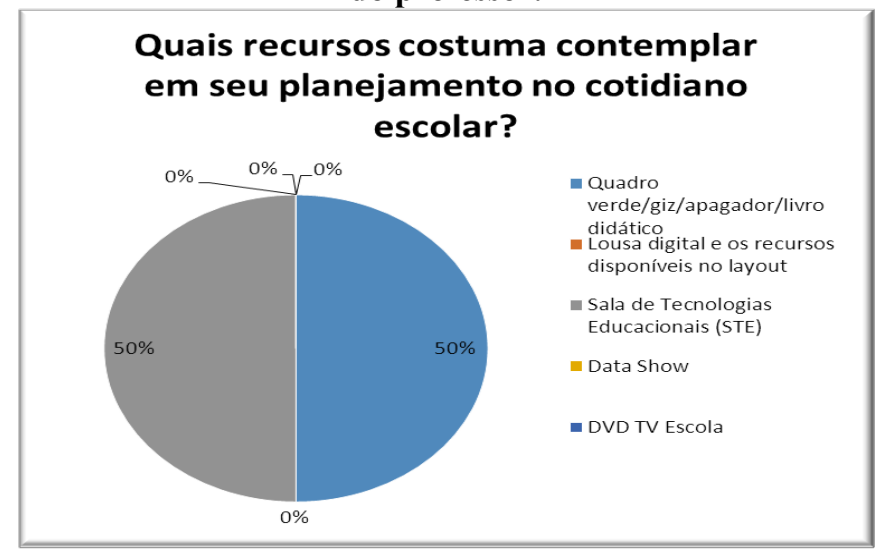

Fonte: Elaboração da autora com base no questionário aplicado.

Figura 5 - Frequência de utilização da lousa digital.

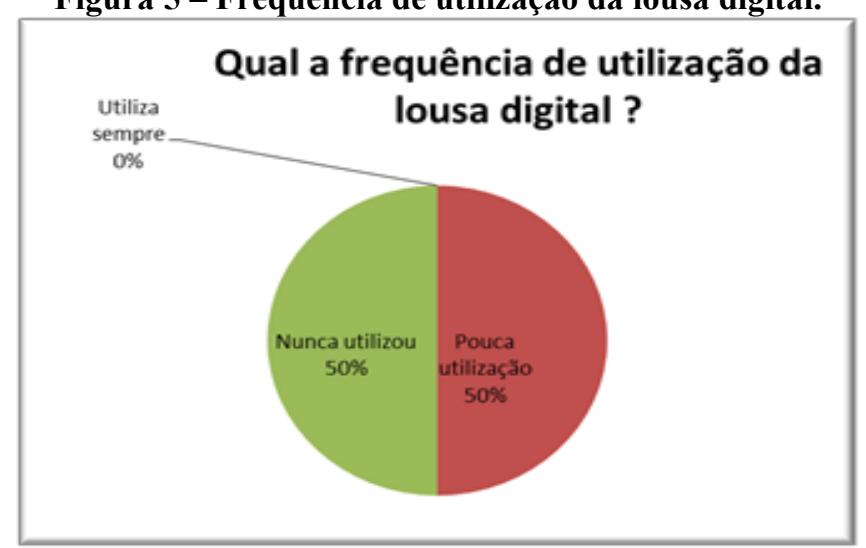

Fonte: Elaboração da autora com base no questionário aplicado.

A figura 5 (cinco) evidencia o questionamento da frequência que os docentes utilizam a lousa digital e constatou - se 50\% pouca utilização e 50\% nuca utilizou.

Desta forma, ao comprar as figuras 4 (quatro) e 5 (cinco) percebe-se a discrepância entre os resultados dos entrevistados, não contemplaram a lousa digital no planejamento, sendo algo

\section{SEMINÁRIO DE EDUCAÇÃO A DISTÂNCIA}




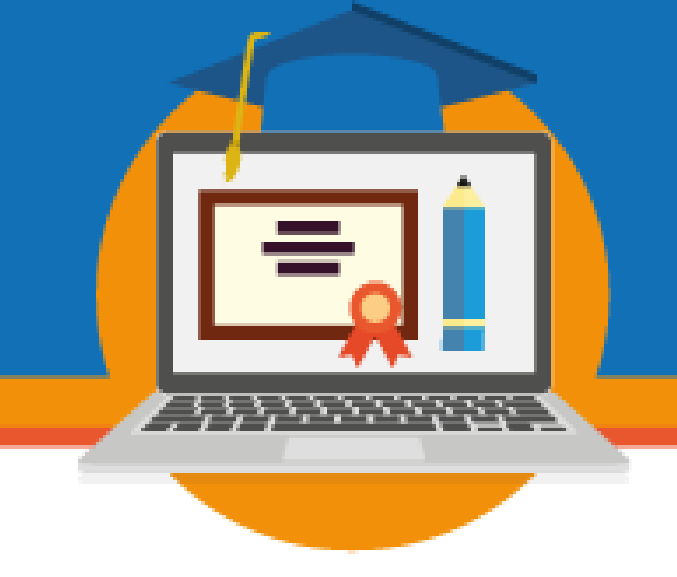

questionável para a organização do trabalho pedagógico docente ao selecionar os recursos que serão utilizados em suas metodologias.

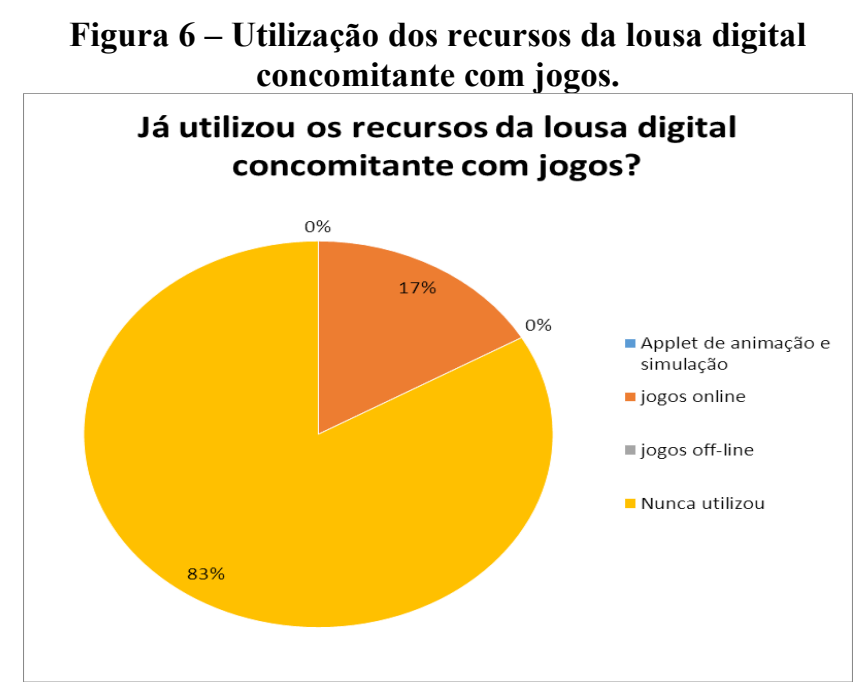

Fonte: Elaboração da autora com base no questionário aplicado.

A figura $6,83 \%$ dos docentes que participaram da formação continuada responderam que nunca utilizaram a lousa digital concomitante com as possibilidades da $W E B 2.0$ e somente $17 \%$ que corresponde a um docente utilizou a lousa com jogos online.

Figura 7 - Lousa digital como recurso facilitador do processo de ensino e de aprendizagem dos alunos

Em sua opinião, a lousa dgital facilita o processo de ensino e de aprendizagem dos alunos?

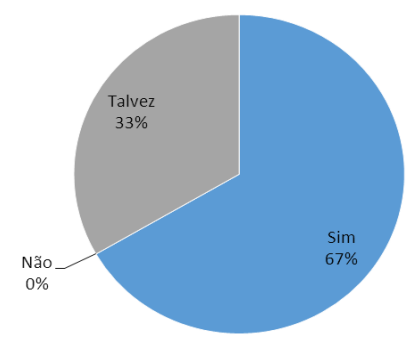

Fonte: Elaboração da autora com base no questionário aplicado.

\section{SEMINÁRIO DE EDUCAÇÃO A DISTÂNCIA}


A figura 7 (sete), contempla as respostas dos 6 (seis) docentes mediante a seguinte indagação: Em sua opinião, a lousa digital facilita o processo de ensino e de aprendizagem dos alunos? $67 \%$ dos entrevistados responderam que sim porque contribui para o ensino e a aprendizagem dos alunos e 33\% responderam que talvez. Ao analisar as respostas pode-se perceber que os professores não conseguiram executar as propostas de atividades com o uso da lousa digital em suas unidades escolares. Possivelmente a proposta da formação continuada tenha que passar por uma revisão buscando simplificar as atividades que a serem desenvolvidas.

Desta forma Kenski (2007) caracteriza a sociedade moderna como um espaço para formação das diversas gerações, possibilitando o domínio de conhecimento para melhorar as especificidades da vida. Percebe-se que o desafio da construção do conhecimento com a utilização da lousa digital vislumbra prospectivamente nas escolas públicas do município de Corumbá, constituindo-se desafios vividos pelos diferentes segmentos educacionais, não bastando somente estimulo para propor inovação, é também oportunizar melhor desenvolvimento dos docentes sugerindo que os mesmos incorporem em sua prática o uso da lousa digital, sendo o mediador destes recursos revendo sua formação inicial, em virtude das exigências da sociedade oferecendo aos alunos melhores recursos para auxiliar na consolidação das atividades propostas no cotidiano escolar, favorecendo formação adequada para a utilização das mídias a serviço da educação.

\section{Considerações Finais}

Em vista dos resultados após um ano da formação realizada, a investigação empreendida foi possível constatar que a formação continuada também constitui em formação inicial em diversas disciplinas. Não utiliza as tecnologias digitais como recurso didático-pedagógico, por mais que os professores dos anos inicias demonstraram estímulo em utilizar os recursos propostos e em inserir as funcionalidades da lousa digital nas atividades que seriam desenvolvidas nos anos inicias, entende-se que será necessário continuar estimulando a formação continuada com a utilização da lousa digital aos docentes das séries inicias considerando o planejamento e os direitos de aprendizagem dos alunos.

\section{SEMINÁRIO DE EDUCAÇÃO A DISTÂNCIA}

EaD na região Centro-Oeste: Institucionalização, Limites e Potencialidades

12 a 14 de abril de 2018 - Campo Grande/MS 


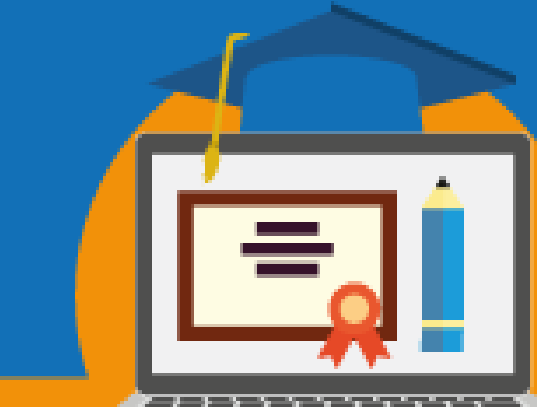

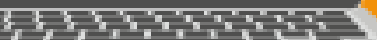

O projeto de formação da lousa digital terá que repassar por ajustes para facilitar a sua inserção como recurso no planejamento do docente, realizar novas possibilidades de utilização, considerando as ações e quadro de direitos de aprendizagem dos alunos dos anos iniciais do ensino fundamental.

\section{Referências}

ARRUDA, M. Humanizar o infra - humano - A formação do ser humano integral. Petrópolis: Vozes, 2003.

BRASIL. Secretaria de Educação Fundamental. B823p Parâmetros curriculares nacionais: língua portuguesa /Secretaria de Educação Fundamental. - Brasília: 144p.

BRASIL. Secretaria de Educação Fundamental. Parâmetros curriculares nacionais: matemática/ Secretaria de Educação Fundamental. - Brasília: MEC/SEF, 1997.142p.

BRASIL. Secretaria de Educação Básica. Diretoria de Apoio à Gestão Educacional. Pacto Nacional pela Alfabetização na Idade Certa: Apresentação / Ministério da Educação, Secretaria de Educação Básica, Diretoria de Apoio à Gestão Educacional. - Brasília: MEC, SEB, 2014.

KENSKI, Vani Moreira. Novas tecnologias, o redimensionamento do espaço e do tempo e os impactos no trabalho docente. Disponível em $<$ http://www.ufba.br/ prossiga/vani.htm $>$. Acesso em 01/04/2016.

LOPES, M. C. L. P. Formação e prática docente na cibercultura? Algumas reconfigurações. 2016. Palestra virtual pelo recurso digital Hangouts.

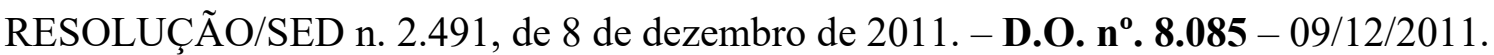

VALENTE, José Armando (org). O computador na sociedade do conhecimento. Campinas: UNICAMP/NIED, 1999. 